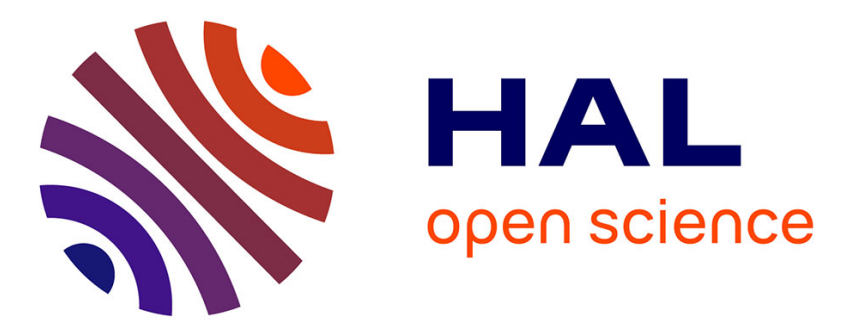

\title{
PET metabolic imaging of time-dependent reorganization of olfactory cued fear memory networks in rats
}

Anne-Marie Mouly, Caroline Bouillot, Nicolas Costes, Luc Zimmer, Nadine Ravel, Philippe Litaudon

\section{To cite this version:}

Anne-Marie Mouly, Caroline Bouillot, Nicolas Costes, Luc Zimmer, Nadine Ravel, et al.. PET metabolic imaging of time-dependent reorganization of olfactory cued fear memory networks in rats. Cerebral Cortex, In press. hal-03358716

\section{HAL Id: hal-03358716 https://hal.science/hal-03358716}

Submitted on 29 Sep 2021

HAL is a multi-disciplinary open access archive for the deposit and dissemination of scientific research documents, whether they are published or not. The documents may come from teaching and research institutions in France or abroad, or from public or private research centers.
L'archive ouverte pluridisciplinaire HAL, est destinée au dépôt et à la diffusion de documents scientifiques de niveau recherche, publiés ou non, émanant des établissements d'enseignement et de recherche français ou étrangers, des laboratoires publics ou privés. 


\section{Cerebral Cortex}

\section{PET metabolic imaging of time-dependent reorganization of olfactory cued fear memory networks in rats}

\begin{tabular}{|r|l|}
\hline Journal: & Cerebral Cortex \\
\hline Manuscript ID & Draft \\
\hline Danuscript Type: & Original Article \\
\hline Author: & $\mathrm{n} / \mathrm{a}$ \\
\hline Complete List of Authors: & $\begin{array}{l}\text { Mouly, Anne-Marie; Centre de Recherche en Neurosciences de Lyon, } \\
\text { CNRS UMR 5292 - INSERM U1028 - University Lyon1 } \\
\text { Bouillot, Caroline; CERMEP, Animage } \\
\text { Costes, Nicolas; CERMEP, PET } \\
\text { Zimmer, LuC; CRNL, BIORAN } \\
\text { Ravel, Nadine; Centre de Recherche en Neurosciences de Lyon, CMO } \\
\text { Litaudon, P; Centre de Recherche en Neurosciences de Lyon, Lyon } \\
\text { Neuroscience Research Center }\end{array}$ \\
\hline Keywords: & $\begin{array}{l}\text { [18F]FDG micro PET, Recent memory, Remote memory, System-level } \\
\text { consolidation, Odor fear conditioning }\end{array}$ \\
\hline & \\
\hline
\end{tabular}


PET metabolic imaging of time-dependent reorganization of olfactory cued fear memory networks in rats

Anne-Marie Mouly 1, Caroline Bouillot 2, Nicolas Costes 2 ${ }^{2}$, Luc Zimmer 1,2,3, Nadine Ravel ${ }^{1}$, Philippe Litaudon ${ }^{1,{ }^{*}}$

${ }^{1}$ Lyon Neuroscience Research Center, CNRS UMR 5292, INSERM U1028, Université Claude Bernard Lyon 1, CH Le Vinatier Bâtiment 462, 95 Bd Pinel, 69675 BRON Cedex, France

${ }^{2}$ CERMEP-Life Imaging, 59 Boulevard Pinel, 69677 Bron, France

${ }^{3}$ Hospices Civils de Lyon, Lyon, France

\section{* Corresponding author :}

Philippe Litaudon

Address: Lyon Neuroscience Research Center, CNRS UMR5292 - Inserm U1028 Université Lyon 1 - Université de Lyon; Centre Hospitalier Le Vinatier - Bâtiment 462 - Neurocampus, 95 boulevard Pinel, 69675 Bron Cedex, France

Email address: philippe.litaudon@cnrs.fr

Tel: 33481106569

Running title: microPET imaging of odor fear memory 


\begin{abstract}
Memory consolidation involves reorganization at both the synaptic and system levels. The latter involves gradual reorganization of the brain regions that support memory and has been mostly highlighted using hippocampal-dependent tasks. The standard memory consolidation model posits that the hippocampus becomes gradually less important over time in favor of neocortical regions. By contrast, this reorganization of circuits in amygdala-dependent tasks has been less investigated. Moreover, this question has been addressed using primarily lesion or cellular imaging approaches thus precluding the comparison of recent and remote memory networks in the same animals. To overcome this limitation, we used microPET imaging to characterize, in the same animals, the networks activated during the recall of a recent vs remote memory in an olfactory cued fear conditioning paradigm. The data highlighted the drastic difference between the extent of the two networks. Indeed, while the recall of a recent odor fear memory activates a large network of structures spanning from the prefrontal cortex to the cerebellum, significant activations during remote memory retrieval are limited to the piriform cortex. These results strongly support the view that amygdala-dependent memories also undergo system-level reorganization, and that sensory cortical areas might participate in the long-term storage of emotional memories.
\end{abstract}

\title{
Keywords
}

[18F]FDG micro PET; Cued Fear conditioning; Recent memory; Remote memory; System-level consolidation; Odor 


\section{Introduction}

It is known from a long time that new memories are gradually stabilized from an initially labile state to a more permanent state through consolidation processes (Müller and Pilzecker 1900). Consolidation involves reorganization at both the synaptic and system levels (Dudai 2004). Synaptic consolidation refers to cellular and molecular modifications at the synaptic level and occurs over relatively short periods of time following learning acquisition, while system consolidation involves large-scale circuit reorganization and can encompass several days or months following the initial learning episode (Frankland and Bontempi 2005).

According to the standard memory consolidation model, recent declarative memories are initially hippocampus-dependent but are progressively reorganized as time passes (Winocur et al. 2010; Squire et al. 2015). Following training, there is continued interplay between the hippocampus and relevant neocortical regions, with the hippocampus becoming gradually less important over time for storage and retrieval, and a more permanent memory developing in distributed regions of the neocortex. This model is supported by results from cellular imaging and pharmacological inactivation studies in animals (Bontempi et al. 1999; Frankland et al. 2004; Maviel et al. 2004), showing that recall of recent spatial and contextual memories is associated with activation of the hippocampus, and inactivating the hippocampus preferentially disrupts the recall of these recent memories. By contrast, as these memories get older, their recall is predominantly associated with activation of cortical regions such as the prefrontal, frontal, anterior cingulate, retrosplenial and temporal cortices and inactivation of the prelimbic or anterior cingulate cortices block recall of remote memory.

Of note, system consolidation has been mostly investigated using hippocampaldependent tasks like spatial learning paradigms (Bontempi et al. 1999; Maviel et al. 
2004), or contextual fear conditioning (Frankland et al. 2004). By contrast, the reorganization of circuits with the passage of time in amygdala-dependent tasks like cued fear conditioning, has been much less investigated (Bergstrom 2016).

In cued fear conditioning, a discrete sensory cue predicts the arrival of a foot-shock and information about the sensory cue and shock converges in the lateral amygdala nucleus via thalamic and cortical inputs and triggers synaptic modifications necessary for memory consolidation (LeDoux 2000; Maren 2001). The lateral amygdala then communicates with the central amygdala nucleus, which sends projections to different structures in the brainstem and in the hypothalamus that orchestrate conditioned fear autonomic and motor responses. While the amygdala plays a key role in the acquisition, storage and retrieval of cued fear memories, there are now a series of studies examining the role of sensory cortices in both recent and remote cued fear memory retrieval (Grosso et al. 2015a; Grosso et al. 2015b). Most of these studies concern the auditory cortex. First, electrophysiological and pharmacological studies have shown that auditory stimuli paired with footshock induce robust changes of synaptic strength in the auditory cortex (Quirk et al. 1997; Weinberger 2007; Letzkus et al. 2011), and that some of these learning-related changes are driven by the amygdala (Chavez et al. 2009) suggesting that the amygdala may strengthen emotional memory trace formation occurring in the auditory cortex. Second, Sacco and Sacchetti (2010) performing localized excitotoxic lesions of different sensory cortices, demonstrated temporally graded deficits in the retrieval of remote fear memory. Indeed, lesions of the auditory cortex disrupted remote, but not recent, auditory cued fear memory. In the same way, lesions of the piriform cortex and visual cortex disrupted remote but not recent olfactory and visual cued fear memory, respectively. Similarly, a pharmacological study showed that blockade of NMDA receptors in the posterior 
piriform cortex decreased remote memory performance while recent memory was unaffected (Hegoburu et al. 2014). These data support the view that emotional memories, like hippocampal-dependent memories, undergo some kind of system-level reorganization, with the sensory cortices being involved in remote but not recent fear memory retrieval. Importantly, in contrast to what happens for hippocampal-dependent memories showing a dispensable role for the hippocampus in remote memory retrieval, the amygdala continues to be crucially involved in fear expression during remote memory retrieval (Bergstrom 2016).

So far, system-level reorganization of amygdala-dependent cued fear memories has been investigated primarily through lesion or inactivation experiments and, to a lesser degree, using autoradiography or histochemistry imaging techniques, thus precluding the comparison of recent and remote memory networks in the same animals. To address this question, we performed 18F-fluorodeoxyglucose ([18F]FDG) positron emission tomography (PET) imaging in rats engaged in an odor fear conditioning paradigm. The key advantage of PET compared to other imaging approaches is that the PET radiotracer allows the whole-brain function to be examined without the confounding effects of anesthesia during radiotracer uptake. Indeed, the animal is awake and freely moving outside the PET scanner during $\left[{ }^{18} \mathrm{~F}\right] \mathrm{FDG}$ uptake, allowing the assessment of brain activation when the animal is engaged in a behavioral task (Jang et al. 2009; Sung et al. 2009). Moreover, [ ${ }^{18}$ F]FDG PET imaging can be used for serial examination of metabolic function in the same animal (Kornblum et al. 2000). In a recent study, we brought the first evidence that $\left[{ }^{18}\right.$ F]FDG PET was a powerful tool to study odor representation in large-scale rodent neuronal networks (Litaudon et al. 2017). Here we capitalized on this observation to investigate system-level reorganization in odor fear conditioning. 


\section{Material and methods}

\section{Animals}

All experiments were conducted in strict accordance with the European Community Council Directive of September 22, 2010 (2010/63/UE), and received approval from the French national ethics committee (APAFIS \#8682-201701261053886v3). Care was taken at all stages to minimize stress and discomfort to the animals. Data were obtained from 18 male Long Evans rats (10 weeks, $287 \pm 20 \mathrm{~g}$ at the beginning of the experiment, Charles River, L'Arbresle, France). They were group-housed at $23^{\circ} \mathrm{C}$ and maintained under a 12/12 h light/dark cycle (lights on from 8 A.M. to 8 P.M.). Food and water were available ad libitum. At their arrival, rats were randomly assigned to one of the two experimental groups.

\section{Experimental apparatus}

The apparatus has been described in detail in a previous study (Hegoburu et al. 2011). It consisted of a plexiglass cage (diameter $20 \mathrm{~cm}$, height $30 \mathrm{~cm}$, EMKA Technologies) placed in a sound attenuating cage (length, $60 \mathrm{~cm}$; width, $60 \mathrm{~cm}$; height, $70 \mathrm{~cm}, 56-\mathrm{dB}$ background noise). The bottom of the animal chamber was equipped with a shock floor connected to a programmable Coulbourn shocker (Bilaney Consultants GmbH). Three Tygon tubing connected to a programmable custom olfactometer were inserted in the tower on the top of the cage to deliver air and odorants. Deodorized air flowed constantly through the cage $(2 \mathrm{l} / \mathrm{min})$. When programmed, an odor was introduced smoothly in the air stream through the switching of a solenoid valve (fluid automation systems, $\mathrm{CH}-1290$ Versoix), thus minimizing its effect on change in pressure. The bottom of the animal chamber had a port connected to a ventilation pump which could draw air out of the plethysmograph (at a rate of up to $2 \mathrm{l} / \mathrm{min}$ ) thus maintaining a 
constant airflow. Animal's behavior was monitored with two video cameras placed on the walls of the sound-attenuating cage.

\section{Fear conditioning paradigm}

\section{Conditioning}

The training protocol is illustrated in figure 1. The animals were handled individually and placed in the experimental apparatus (two sessions of 30 min per day) during the two days preceding the beginning of the experiment to minimize stress induced by exposure to a novel environment and to familiarize them with being manipulated. For the conditioning session, rats from the Fear group $(F, n=9)$ were allowed free exploration during the first $4 \mathrm{~min}$, and then an odor (1:10 peppermint vapor to air) was introduced into the cage for 20 seconds, the last second of which overlapped with the delivery of a 0.4-mA foot-shock. The animal received 10 odor-shock trials, with an intertrial interval of $4 \mathrm{~min}$. After the last pairing, the animal returned to its home cage. Rats in the Control group $(C, n=9)$ followed the same protocol except that they received 10 presentations of 20 s-odor but no shock.

\section{Retention test}

The conditioned fear response was assessed in both groups during two retention tests: one $24 \mathrm{~h}$ after conditioning (recent memory, C1 and F1) and another 30 days later (remote memory, C2 and F2) (Fig. 1). The testing cage was equipped with new visual cues and with a plastic floor to avoid contextual fear expression. Four hours prior to each retention test session, the rats were food-deprived but were allowed free access to water. This restriction was applied to selectively maximize and homogenize $\left[{ }^{18} \mathrm{~F}\right]$ FDG uptake at the brain level (Fueger et al. 2006). Immediately before the start of the retention session, the animals were briefly anesthetized with isoflurane $(5 \%$ for 
induction and $2-2.5 \%$ for maintenance), and an intravenous catheter was placed in the tail vein. Immediately after bolus $\left[{ }^{18} \mathrm{~F}\right] \mathrm{FDG}$ injection (10 $\left.\pm 1.6 \mathrm{MBq}, 500 \mu \mathrm{l}\right)$, the catheter was removed and isoflurane was discontinued. Then, the rat was placed in the testing cage, and allowed a $5 \mathrm{~min}$ period to recover from anesthesia. The learned odor was then presented ten times for $20 \mathrm{~s}$ with a 2-min inter-trial interval. The fear memory strength was assessed by measuring the duration of the animal's freezing response during the retention test. Freezing behavior defined as the absence of any visible movement except that due to breathing (Blanchard and Blanchard 1969) was automatically detected using a Labview homemade software and further verified by an experimenter (for a detailed description, see Dupin et al. 2019). The animal's freezing response was quantified during each 20 s odor presentation. The obtained values were then expressed as a percentage of the sampled period total duration, averaged across the trials for a given animal, and averaged among animals of the same experimental group. Freezing amounts were compared using a two-way repeated-measures ANOVA, with group (Control versus Fear) as an independent factor and age of memory (recent vs remote) as a repeated factor, followed by post-hoc Fisher tests for pairwise comparisons. For all the statistical comparisons performed, the significance level was set at 0.05 .

\section{PET imaging}

\section{Data acquisition}

At the end of each retention test session, the rats were anesthetized with isoflurane and placed in a prone position on the bed of the scanner, and an emission scan lasting 20 minutes was initiated (Fig. 1). To minimize head movement, the rat was head-fixed with ear bars and a tooth bar in a head holder. Its body temperature was maintained at $37 \pm 0.2{ }^{\circ} \mathrm{C}$ using a dedicated heating pad and the respiration rate was monitored 
using a pressure sensor. Data were acquired in list-mode using a dedicated small animal PET/CT scanner manufactured by Inveon (Siemens, Erlangen, Germany). The scanner has an axial field of view of $12.7 \mathrm{~cm}$ and a spatial resolution of $1.8 \mathrm{~mm}$ full width at half maximum (FWHM) (Bao et al. 2009). This nominal resolution means that two sources of the same activity separated by less than $1.8 \mathrm{~mm}$ cannot be distinguished. Nevertheless, smaller sources can be detected and quantified. A CT scan was performed in the same position immediately after PET emission scan to correct for tissue attenuation. The images were reconstructed in four frames of five minutes each with attenuation as well as scatter correction by a 3D-filtered backprojection algorithm (Hamming filter; cut-off frequency 0.5 cycles/pixel) and a zoom factor of two. This led to reconstructed volumes of 159 slices comprising $128 \times 128$ voxels in a bounding box of $49.7 \times 49.7 \times 126 \mathrm{~mm}$ with voxel size $0.388 \times 0.388 \times$ $0.796 \mathrm{~mm}$. After scanning, the animals were returned to their home cages.

\section{Data analyses}

Data processing was carried out using statistical parametric mapping software (SPM12, Welcome trust center for neuroimaging, London; http://www.fil.ion.ucl.ac.uk/spm/). Individual PET images were spatially normalized to a custom PET $\left[{ }^{18} \mathrm{~F}\right]$ FDG template made from the MRI template in the space of the Lancelot rat brain atlas (Lancelot et al. 2014) and resliced to a resolution of $0.1 \times 0.1 \mathrm{x}$ $0.205 \mathrm{~mm}$. Lancelot et al. (2014) showed that the sensitivity of detection in the subject space does not differ after spatially normalizing PET images in the template space via a functional template. Furthermore, this method resulted in excellent reproducibility. The normalized brain images were smoothed using a Gaussian filter (isotropic $0.5 \mathrm{~mm}$ full width at half maximum) and subsequently masked to remove extra-cerebral activity. Subsequently, PET image intensities were normalized using the standardized uptake 
value (tissue activity concentration/injected dose $\mathrm{x}$ body weight). A voxel-based SPM analysis was performed within a one-way measures ANOVA design with C1, C2, F1 and F2 as factors. Whole-brain mean [ $\left.{ }^{18} \mathrm{~F}\right] \mathrm{FDG}$ activity computed for each scan within the template mask of the brain was used for ANCOVA normalization. Statistical maps data were thresholded at $p<0.001$ (uncorrected) with an extent threshold of 100 voxels (0.205 mm3). Such a cluster-forming threshold is a reasonable statistical level inference to identify regions that are localized enough to be interpretable (Woo et al. 2014).

\section{Results}

\section{Behavioral data}

In both groups of rats (Control and Fear groups), two retention tests were carried out respectively $24 \mathrm{~h}$ (recent memory) and 30 days (remote memory) after the acquisition session. Freezing behavior measured in the two groups during each test session is shown in Figure 2. Due to technical issues, three video recordings could not be analyzed. A two-way repeated-measures ANOVA revealed a main effect of group $\left(F_{1,13}=70.467, p<0.001\right)$ but no effect of memory age $\left(F_{1,13}=0.100, p=0.757\right)$. Further post-hoc comparisons showed that for both retention tests, the level of freezing in response to the odor is significantly higher in the Fear group than in the Control group. In the two groups, the level of freezing is not different between recent and remote memory.

\section{PET imaging data}

First, the functional network related to recent memory was assessed by contrasting Fear group $(n=9)$ and Control group $(n=9)$ maps obtained during the 24 h retention test (F1 VS $\mathrm{C} 1$ contrast). This analysis revealed several clusters showing significant 
increases in $\left[{ }^{18} \mathrm{~F}\right] \mathrm{FDG}$ uptake along the brain antero-posterior axis. The main activated brain areas are reported in Table 1 (all the significant clusters are reported in supplementary table 1). First, regional brain activations were observed in several olfactory cortical areas including the anterior piriform cortex, the posterior piriform cortex, the anterior olfactory nucleus, and the entorhinal cortex (Fig. 3a-g,j). Clusters of significant voxels were also observed in the prefrontal cortex including the prelimbic cortex and the cingulate cortex (Fig. 3a-d), in the somatosensory cortex including the barrel field cortex (Fig. 3c-f). In addition to cortical structures, significant increases in glucose metabolism were observed in the basolateral amygdaloid complex (Fig. 3f,g), the striatum (Fig. 3b,c-e), the thalamus (Fig. 3f,g) and the hippocampal formation including dorsal and ventral hippocampus and the subiculum (Fig. 3g-j). Finally, activations were also observed in the ventral part of the periaqueductal gray (Fig. 3j,k) and in several modules of the cerebellum (Fig. 3l,m). We did not observe decrease in $\left[{ }^{18} \mathrm{~F}\right] \mathrm{FDG}$ uptake.

We then investigated the functional network related to remote memory by contrasting the maps obtained for the Fear group $(n=9)$ and Control group $(n=8$, one animal could not be recorded due to a technical issue with the PET scanner) during the 30 days retention test (F2 VS C2). In striking contrast with the network activated during the recent memory retention test, the remote memory network was limited to posterior piriform cortex (Fig. 4, Table 2).

\section{Discussion}

The present study investigated the fear neural networks by questioning the existence of system-level reorganization of amygdala-dependent emotional memories as assessed using odor fear conditioning. Our study is the first to our knowledge to describe the networks involved in recent and remote fear memory in the same animals 
using $\left[{ }^{18} \mathrm{~F}\right] \mathrm{FDG}$ PET. The data showed that the recall of a recent odor fear memory activates a large network of structures spanning from the prefrontal cortex to the cerebellum. In sharp contrast, in our experimental conditions, remote fear memory retrieval activates significantly a very restricted network limited to a single cortical area, the piriform cortex.

\section{Behavior}

The strength of recent and remote odor memories was assessed by measuring the freezing response to the learned odor during two retention tests carried out respectively $24 \mathrm{~h}$ and 30 days after the conditioning session. The data showed that the level of freezing was high and similar during the two retention tests, which indicates that the strength of the remote odor memory was equivalent to that of the recent one. This data is important because the recent memory test consisted in the repeated presentation of the learned odor alone, which could have triggered extinction of the memory, resulting in low levels of freezing during the remote memory test. This was not the case, suggesting that the learned association was strong and resistant to extinction processes that could have occurred during the recent memory test.

\section{Recent memory network}

The recent memory network includes olfactory cortical areas and brain areas classically described as playing a critical role in cued fear memory, like the amygdala, the prefrontal cortex and the periaqueductal grey. This network also includes less classical brain areas like the cerebellum, the striatum and the somatosensory cortex.

\section{Olfactory cortical network}


Our data showed bilateral activations in primary olfactory areas. Among them, the piriform cortex is the largest area and is classically divided into two parts: the anterior $(\mathrm{aPC})$ and posterior (pPC) piriform cortex.

Previous studies in the literature have highlighted that the aPC is preferentially involved in sensory processes and simple forms of memory, such as short-term habituation (Wilson 1998a, 1998b; Kadohisa and Wilson 2006), pattern completion (Barnes et al. 2008), and perceptual learning (Wilson and Stevenson 2003). In contrast, the pPC is involved in cognitive mnesic processes, including learning and recall of associations between odorants and information from other sensory modalities (Litaudon et al. 1997, 2003; Chabaud et al. 1999, 2000; Mouly et al. 2001; Mouly and Gervais 2002; Mouly and Di Scala 2006). The activation reported here in aPC and pPC is in accordance with previous studies showing the role of aPC (Barnes et al. 2011; Chen et al. 2011) and pPC (Sevelinges et al. 2004, 2008; Jones et al. 2007; Hegoburu et al. 2009; Dupin et al. 2020) in odor fear conditioning. They are also in agreement with recent data showing that olfactory fear conditioning activates sparse and distributed ensembles of neurons in the mouse piriform cortex and that specific silencing of these neurons impairs odor fear memory recall (Meissner-Bernard et al. 2019).

The activation observed in the anterior olfactory nucleus (AON) is more surprising. A few studies have shown that AON was activated during context-odor association (Aqrabawi and Kim 2020; Levinson et al. 2020). More interestingly, a study by Staples et al. (2005) showed that AON was activated during predator odor contextual fear conditioning. Finally, our results confirmed data from a previous study showing that fos expression is enhanced in the AON following odor fear conditioning (Funk and Amir 2000).

\section{Activation in the classically described fear conditioning network}




\section{Amygdala}

It is known from a long time that circuits within the amygdala are essential to the acquisition, storage, and retrieval of contextual and cued (mostly auditory) fear memories (LeDoux 2000; Maren 2001; Pape and Pare 2010). Specifically, selective lesions of the basolateral amygdaloid complex (BLA) produce severe deficits in both the acquisition and expression of Pavlovian fear conditioning independent of the stimulus modality used for the CS (LeDoux et al. 1990; Campeau and Davis 1995; Maren et al. 1996; Cousens and Otto 1998). In our study, the retrieval of recent odor fear memory activates the BLA and confirms its role in the expression of odor fear memory highlighted in previous studies using electrophysiological recordings (Rosenkranz and Grace 2002; Sevelinges et al. 2004, 2007; Dupin et al. 2019, 2020), intracerebral microdialysis monitoring (Hegoburu et al. 2009) and lesion or pharmacological inactivation (Cousens and Otto 1998; Kilpatrick and Cahill 2003; Walker et al. 2005; Hegoburu et al. 2014).

\section{Prefrontal cortex}

Our data showed an activation of the median prefrontal cortex (mPFC), and more specifically its prelimbic part, during recent odor fear memory recall. In rodents, the mPFC is subdivided into infralimbic (IL) and prelimbic (PL) regions, which have been described as having opposite influences on fear behavior: while the PL is involved in the expression of fear, the IL is rather involved in the suppression of fear during extinction learning and retrieval (Sierra-Mercado et al. 2011; Milad and Quirk 2012; Giustino and Maren 2015). There are now several lines of evidence linking activity in the prelimbic cortex, with the retrieval of auditory cued fear conditioning (Corcoran and Quirk 2007; Burgos-Robles et al. 2009; Choi et al. 2010; Sierra-Mercado et al. 2011; Courtin et al. 2014; Do-Monte et al. 2015). Here we show that the PL is also activated 
during the retrieval of a recent odor fear memory, suggesting its involvement is independent of the sensory modality of the learned CS. These data extend previous electrophysiological data showing that the PL might be involved in the encoding of the temporal relationships between an odor CS and the US during acquisition of an odor fear conditioning (Dupin et al. 2020). In addition to median prefrontal cortex, our data showed that the cingulate cortex was activated during odor fear memory retrieval as observed for auditory cued fear memory (Tang et al. 2005).

\section{Hippocampus}

Here we report an activation in both dorsal and ventral parts of the hippocampus during the retrieval of a recent odor fear memory. Maren and Holt (2004), comparing the effects of pharmacological inactivation of the dorsal hippocampus or ventral hippocampus on Pavlovian auditory fear conditioning in rats, reported that inactivation of the ventral, but not the dorsal hippocampus, induced impairments in the acquisition of the learning. They also showed that postraining lesion of the ventral hippocampus disrupted the expression of conditioned fear to the tone. Thus, the ventral hippocampus might be involved in the acquisition and expression of auditory fear memory. The dorsal hippocampus, as for it, is thought to play a critical role in contextual fear conditioning (Anagnostaras et al. 2001; Rudy 2009; Maren et al. 2013), and does not seem to be involved in cued auditory fear conditioning (Kim and Fanselow 1992; Phillips and LeDoux 1992, 1994). In the present study, although the testing cage was equipped with new visual cues and with a plastic floor for the retention test the animals might have partly recognized the initial training cage thus expressing contextual fear in addition to odor fear. This could explain why both ventral and dorsal parts of the hippocampus were activated during the recent memory test. 
Periaqueductal grey (PAG)

The PAG has long been implicated as the organizer of the different behavioral components of the response to threat (LeDoux 2000; Tovote et al. 2016). Previous studies showed that activation of the ventrolateral periaqueductal gray (vIPAG) by the central amygdala (CeA) drives immobility and lesions of the vIPAG reduce the conditioned freezing response (LeDoux et al. 1988; Vianna et al. 2001), while expression of conditioned freezing is associated with increased vIPAG neuronal activation (Carrive et al. 1997). In a recent study, Tovote et al. (2016) identified an inhibitory pathway from the CeA to the vIPAG that produces freezing by disinhibition of vIPAG excitatory outputs to pre-motor targets in the magnocellular nucleus of the medulla. Our data confirm the involvement of the vIPAG during the retrieval of a recent odor fear memory that is accompanied by a high level of freezing in the trained animals.

\section{Activations beyond the classically described fear conditioning network}

In the present study we found activation in several modules of the cerebellum. This is in accordance with the data reported in the literature showing that the cerebellum has functional connections with fear-related areas, including the PAG, the amygdala, and the prefrontal cortex (Koutsikou et al. 2014; Frontera et al. 2020; Vaaga et al. 2020). Nevertheless, only few studies have directly investigated cerebellar contributions to fear behavior. Thus, Pavlovian fear conditioning affects cerebellar plasticity (Sacchetti et al. 2004), and cerebellar lesions or inactivation modulate freezing response (Supple et al. 1987; Koutsikou et al. 2014). Activation observed in the present study in Crus 2 lobule, as also reported in a previous study (Litaudon et al. 2017), is in accordance with previous data showing that Crus 2 is activated by whisker stimulation (Sharp et al. 1989; Bosman et al. 2010) and by stimulation of the skin of the snout (Armstrong and Drew 1980), both being associated with sniffing. This result could also be related to 
the activations we observed in the somatosensory cortex including barrel field cortex. These activations might be related to whisker movements, which are coupled with sniffing during exploration of the environment (Welker 1964; Deschênes et al. 2012). Interestingly, Maier et al. (2020) analyzed the nose/nostril representation in the rodent somatosensory cortex using receptive field mapping and subsequent histological reconstruction. Their results reveal previously unknown cytoarchitectonic and physiological properties of the rodent nose somatosensory cortex, potentially enabling it to integrate multiple sensory modalities.

The other brain structure showing increased metabolism during the recent memory test was the striatum, and more specifically its dorsal part. Importantly, the medial posterior dorsal striatum receives inputs from the piriform cortex (McGeorge and Faull 1989) and the amygdala (McDonald 1991). The dorsal striatum has been suggested to be involved in aversive learning in general such as in auditory fear conditioning (Ferreira et al. 2003; Kishioka et al. 2009; Wendler et al. 2014), or in a two-way active avoidance task (Darvas et al. 2011; Wendler et al. 2014) but not in contextual fear conditioning (Ferreira et al. 2003). Our present data are in line with results from Boulanger Bertolus et al. (2014) assessing the activity of the striatum in odor fear conditioning using 2Deoxyglucose autoradiography. They revealed that, in paired rats, the medial part of the posterior striatum showed an increased activity compared to control animals. Thus, the present data extend the role of the dorsal striatum to the retrieval of a recent odor fear memory.

\section{Remote memory network}

The remote memory network revealed using $\left[{ }^{18} \mathrm{~F}\right] \mathrm{FDG}$ uptake was limited to pPC. The present data are in accordance with studies showing the role of PC in remote odor fear 
memory. Indeed, Sacco and Sacchetti (2010) found that excitotoxic lesions of auditory, visual, or olfactory secondary sensory cortices impaired remote, but not recent, fear memories in rats, leading the authors to suggest that sensory cortices support memory storage and retrieval of sensory stimuli that have acquired a behavioral salience with the experience.

Surprisingly, the amygdala did not show an increased activity compared to control group. There is abundant literature showing that the amygdala is involved in fear expression, but very few studies have investigated its role over time in cued fear memories (Bergstrom 2016). In one of these studies the basolateral amygdala was lesioned 1-day, 7-days and 28-days following auditory cued Pavlovian fear conditioning (Maren et al. 1996). At each time point, the expression of cued fear was abolished. These data suggest the dependence of cued fear memory retrieval on amygdala function whatever the age of memory. In the present study, we would thus have expected an activation of the amygdala during remote memory retrieval. It could be the case that the amygdala was still activated, albeit at a lower level or for a very short period of time, that fell below the sensitivity of the $\left[{ }^{18} \mathrm{~F}\right] \mathrm{FDG}$ PET imaging technology. Indeed, we can imagine that for the recall of an old memory, the amygdala, even if it is still necessary, is involved in a transitory way and/or at a lower energy cost.

\section{Limitations}

The present study entails some limitations that need to be considered. Indeed, some technical issues must be considered when using FDG PET. First, the temporal resolution of this technique is poor compared to that of other functional methods. Indeed, $\left[{ }^{18} \mathrm{~F}\right] \mathrm{FDG}$ is irreversibly trapped within tissues over the course of the uptake session, and the final PET image is the cumulative result of all brain activations occurring during the retention test, thus precluding to assess the time course of brain 
activation across the session. Second, the spatial resolution of this technique is limited, making it difficult to assess the activity of small brain areas. Despite these caveats, PET imaging has important advantages. First, compared to other imaging methods like fMRI and optical imaging that require the animal to be anesthetized or head-fixed, probe uptake occurs while the animal is conscious and freely moving. Thus, this technique allows the examination of whole brain function without the confounding effects of anesthesia during radiotracer uptake or animal sacrifice. PET should also be considered as a complementary approach to electrophysiological recording. Indeed, by assessing whole brain activity, even at low spatial resolution, this technique could help to identify otherwise unexplored areas of interest for subsequent electrophysiological recording.

\section{Conclusions}

The present work allowed us to characterize for the first time, in the same animals involved in an olfactory cued fear conditioning paradigm, the networks activated during the recall of a recent vs remote amygdala-dependent memory. The data pinpointed to the drastic difference between the sizes of the two networks. These results bring strong support to the view that amygdala-dependent memories, like hippocampal-dependent memories, undergo system-level reorganization, and that sensory cortical areas might participate in the long-term storage of emotional memories.

Only very few studies have investigated rodent fear memory network using imaging methods initially developed for the human brain. Uselman et al. (2020) used manganese-enhanced MRI to analyze innate fear response to predator odor. In the only other study using PET imaging associated with auditory fear conditioning, Luyten et al. (2012) focused their analysis on the neurocircuitry of contextual anxiety. The 
present study went a step further in the investigation of the fear neural networks by questioning the existence of system-level reorganization using a longitudinal approach. The fact that we highlighted the neuronal network classically described in the literature for fear memory shows that the results obtained with FDG PET are reliable. In addition, by assessing the whole brain activity, our results extend the fear associated network to other less investigated structures.

Overall, our results demonstrate that PET imaging offers a powerful approach for neuroimaging in behaving animals. By enabling longitudinal studies thanks to serial brain imaging of the same subject, PET imaging supports the necessary reduction in the number of animals used in experimental procedures.

\section{References}

Anagnostaras SG, Gale GD, Fanselow MS. 2001. Hippocampus and contextual fear conditioning: recent controversies and advances. Hippocampus. 11:8-17.

Aqrabawi AJ, Kim JC. 2020. Olfactory memory representations are stored in the anterior olfactory nucleus. Nat Commun. 11:1246.

Armstrong DM, Drew T. 1980. Responses in the posterior lobe of the rat cerebellum to electrical stimulation of cutaneous afferents to the snout. J Physiol. 309:357-374.

Bao Q, Newport D, Chen M, Stout DB, Chatziioannou AF. 2009. Performance evaluation of the inveon dedicated PET preclinical tomograph based on the NEMA NU4 standards. J Nucl Med. 50:401-408.

Barnes DC, Chapuis J, Chaudhury D, Wilson DA. 2011. Odor fear conditioning modifies piriform cortex local field potentials both during conditioning and during postconditioning sleep. PloS One. 6:e18130. 
Barnes DC, Hofacer RD, Zaman AR, Rennaker RL, Wilson DA. 2008. Olfactory perceptual stability and discrimination. Nat Neurosci. 11:1378-1380.

Bergstrom HC. 2016. The neurocircuitry of remote cued fear memory. Neurosci Biobehav Rev. 71:409-417.

Blanchard RJ, Blanchard DC. 1969. Crouching as an index of fear. J Comp Physiol Psychol. 67:370-375.

Bontempi B, Laurent-Demir C, Destrade C, Jaffard R. 1999. Time-dependent reorganization of brain circuitry underlying long-term memory storage. Nature. 400:671-675.

Bosman LWJ, Koekkoek SKE, Shapiro J, Rijken BFM, Zandstra F, van der Ende B, Owens CB, Potters J-W, de Gruijl JR, Ruigrok TJH, De Zeeuw CI. 2010. Encoding of whisker input by cerebellar Purkinje cells. J Physiol. 588:3757-3783.

Boulanger Bertolus J, Hegoburu C, Ahers JL, Londen E, Rousselot J, Szyba K, Thévenet M, Sullivan-Wilson TA, Doyère V, Sullivan RM, Mouly A-M. 2014. Infant rats can learn time intervals before the maturation of the striatum: evidence from odor fear conditioning. Front Behav Neurosci. 8:176.

Burgos-Robles A, Vidal-Gonzalez I, Quirk GJ. 2009. Sustained conditioned responses in prelimbic prefrontal neurons are correlated with fear expression and extinction failure. J Neurosci. 29:8474-8482.

Campeau S, Davis M. 1995. Involvement of the central nucleus and basolateral complex of the amygdala in fear conditioning measured with fear-potentiated startle in rats trained concurrently with auditory and visual conditioned stimuli. J Neurosci. $15: 2301-2311$. 
Carrive P, Leung P, Harris J, Paxinos G. 1997. Conditioned fear to context is associated with increased Fos expression in the caudal ventrolateral region of the midbrain periaqueductal gray. Neuroscience. 78:165-177.

Chabaud P, Ravel N, Wilson DA, Gervais R. 1999. Functional coupling in rat central olfactory pathways: a coherence analysis. Neurosci Lett. 276:17-20.

Chabaud P, Ravel N, Wilson DA, Mouly AM, Vigouroux M, Farget V, Gervais R. 2000. Exposure to behaviourally relevant odour reveals differential characteristics in rat central olfactory pathways as studied through oscillatory activities. Chem Senses. 25:561-573.

Chavez CM, McGaugh JL, Weinberger NM. 2009. The basolateral amygdala modulates specific sensory memory representations in the cerebral cortex. Neurobiol Learn Mem. 91:382-392.

Chen C-FF, Barnes DC, Wilson DA. 2011. Generalized vs. stimulus-specific learned fear differentially modifies stimulus encoding in primary sensory cortex of awake rats. J Neurophysiol. 106:3136-3144.

Choi DC, Maguschak KA, Ye K, Jang S-W, Myers KM, Ressler KJ. 2010. Prelimbic cortical BDNF is required for memory of learned fear but not extinction or innate fear. Proc Natl Acad Sci U S A. 107:2675-2680.

Corcoran KA, Quirk GJ. 2007. Activity in prelimbic cortex is necessary for the expression of learned, but not innate, fears. J Neurosci. 27:840-844.

Courtin J, Chaudun F, Rozeske RR, Karalis N, Gonzalez-Campo C, Wurtz H, Abdi A, Baufreton J, Bienvenu TCM, Herry C. 2014. Prefrontal parvalbumin interneurons shape neuronal activity to drive fear expression. Nature. 505:92-96. 
Cousens G, Otto T. 1998. Both pre- and posttraining excitotoxic lesions of the basolateral amygdala abolish the expression of olfactory and contextual fear conditioning. Behav Neurosci. 112:1092-1103.

Darvas M, Fadok JP, Palmiter RD. 2011. Requirement of dopamine signaling in the amygdala and striatum for learning and maintenance of a conditioned avoidance response. Learn Mem. 18:136-143.

Deschênes M, Moore J, Kleinfeld D. 2012. Sniffing and whisking in rodents. Curr Opin Neurobiol. 22:243-250.

Do-Monte FH, Manzano-Nieves G, Quiñones-Laracuente K, Ramos-Medina L, Quirk GJ. 2015. Revisiting the role of infralimbic cortex in fear extinction with optogenetics. J Neurosci. 35:3607-3615.

Dudai Y. 2004. The neurobiology of consolidations, or, how stable is the engram? Annu Rev Psychol. 55:51-86.

Dupin M, Garcia S, Boulanger-Bertolus J, Buonviso N, Mouly A-M. 2019. New Insights from 22-kHz Ultrasonic Vocalizations to Characterize Fear Responses: Relationship with Respiration and Brain Oscillatory Dynamics. eNeuro. 6.

Dupin M, Garcia S, Messaoudi B, Doyère V, Mouly A-M. 2020. Respiration and brain neural dynamics associated with interval timing during odor fear learning in rats. Sci Rep. 10:17643.

Ferreira TL, Moreira KM, Ikeda DC, Bueno OFA, Oliveira MGM. 2003. Effects of dorsal striatum lesions in tone fear conditioning and contextual fear conditioning. Brain Res. 987:17-24.

Frankland PW, Bontempi B. 2005. The organization of recent and remote memories. Nat Rev Neurosci. 6:119-130. 
Frankland PW, Bontempi B, Talton LE, Kaczmarek L, Silva AJ. 2004. The involvement of the anterior cingulate cortex in remote contextual fear memory. Science. $304: 881-$ 883.

Frontera JL, Baba Aissa H, Sala RW, Mailhes-Hamon C, Georgescu IA, Léna C, Popa D. 2020. Bidirectional control of fear memories by cerebellar neurons projecting to the ventrolateral periaqueductal grey. Nat Commun. 11:5207.

Fueger BJ, Czernin J, Hildebrandt I, Tran C, Halpern BS, Stout D, Phelps ME, Weber WA. 2006. Impact of animal handling on the results of 18F-FDG PET studies in mice. J Nucl Med. 47:999-1006.

Funk D, Amir S. 2000. Enhanced fos expression within the primary olfactory and limbic pathways induced by an aversive conditioned odor stimulus. Neuroscience. 98:403406.

Giustino TF, Maren S. 2015. The Role of the Medial Prefrontal Cortex in the Conditioning and Extinction of Fear. Front Behav Neurosci. 9:298.

Grosso A, Cambiaghi M, Concina G, Sacco T, Sacchetti B. 2015a. Auditory cortex involvement in emotional learning and memory. Neuroscience. 299:45-55.

Grosso A, Cambiaghi M, Renna A, Milano L, Roberto Merlo G, Sacco T, Sacchetti B. $2015 \mathrm{~b}$. The higher order auditory cortex is involved in the assignment of affective value to sensory stimuli. Nat Commun. 6:8886.

Hegoburu C, Parrot S, Ferreira G, Mouly A-M. 2014. Differential involvement of amygdala and cortical NMDA receptors activation upon encoding in odor fear memory. Learn Mem. 21:651-655.

Hegoburu C, Sevelinges Y, Thévenet M, Gervais R, Parrot S, Mouly A-M. 2009. Differential dynamics of amino acid release in the amygdala and olfactory cortex during 
odor fear acquisition as revealed with simultaneous high temporal resolution microdialysis. Learn Mem. 16:687-697.

Hegoburu C, Shionoya K, Garcia S, Messaoudi B, Thévenet M, Mouly A-M. 2011. The RUB Cage: Respiration-Ultrasonic Vocalizations-Behavior Acquisition Setup for Assessing Emotional Memory in Rats. Front Behav Neurosci. 5:25.

Jang D-P, Lee S-H, Lee S-Y, Park C-W, Cho Z-H, Kim Y-B. 2009. Neural responses of rats in the forced swimming test: [F-18]FDG micro PET study. Behav Brain Res. 203:43-47.

Jones SV, Stanek-Rattiner L, Davis M, Ressler KJ. 2007. Differential regional expression of brain-derived neurotrophic factor following olfactory fear learning. Learn Mem. 14:816-820.

Kadohisa M, Wilson DA. 2006. Separate encoding of identity and similarity of complex familiar odors in piriform cortex. Proc Natl Acad Sci U A. 103:15206-15211.

Kilpatrick L, Cahill L. 2003. Modulation of memory consolidation for olfactory learning by reversible inactivation of the basolateral amygdala. Behav Neurosci. 117:184-188. Kim JJ, Fanselow MS. 1992. Modality-specific retrograde amnesia of fear. Science. 256:675-677.

Kishioka A, Fukushima F, Ito T, Kataoka H, Mori H, Ikeda T, Itohara S, Sakimura K, Mishina M. 2009. A novel form of memory for auditory fear conditioning at a lowintensity unconditioned stimulus. PloS One. 4:e4157.

Kornblum HI, Araujo DM, Annala AJ, Tatsukawa KJ, Phelps ME, Cherry SR. 2000. In vivo imaging of neuronal activation and plasticity in the rat brain by high resolution positron emission tomography (microPET). Nat Biotechnol. 18:655-660. 
Koutsikou S, Crook JJ, Earl EV, Leith JL, Watson TC, Lumb BM, Apps R. 2014. Neural substrates underlying fear-evoked freezing: the periaqueductal grey-cerebellar link. J Physiol. 592:2197-2213.

Lancelot S, Roche R, Slimen A, Bouillot C, Levigoureux E, Langlois J-B, Zimmer L, Costes N. 2014. A multi-atlas based method for automated anatomical rat brain MRI segmentation and extraction of PET activity. PloS One. 9:e109113.

LeDoux JE. 2000. Emotion circuits in the brain. Annu Rev Neurosci. 23:155-184.

LeDoux JE, Cicchetti P, Xagoraris A, Romanski LM. 1990. The lateral amygdaloid nucleus: sensory interface of the amygdala in fear conditioning. J Neurosci. 10:10621069.

LeDoux JE, Iwata J, Cicchetti P, Reis DJ. 1988. Different projections of the central amygdaloid nucleus mediate autonomic and behavioral correlates of conditioned fear. J Neurosci. 8:2517-2529.

Letzkus JJ, Wolff SBE, Meyer EMM, Tovote P, Courtin J, Herry C, Lüthi A. 2011. A disinhibitory microcircuit for associative fear learning in the auditory cortex. Nature. 480:331-335.

Levinson M, Kolenda JP, Alexandrou GJ, Escanilla O, Cleland TA, Smith DM, Linster C. 2020. Context-dependent odor learning requires the anterior olfactory nucleus. Behav Neurosci. 134:332-343.

Litaudon P, Amat C, Bertrand B, Vigouroux M, Buonviso N. 2003. Piriform cortex functional heterogeneity revealed by cellular responses to odours. Eur J Neurosci. $17: 2457-2461$.

Litaudon P, Bouillot C, Zimmer L, Costes N, Ravel N. 2017. Activity in the rat olfactory cortex is correlated with behavioral response to odor: a microPET study. Brain Struct Funct. 222:577-586. 
Litaudon P, Mouly AM, Sullivan R, Gervais R, Cattarelli M. 1997. Learning-induced changes in rat piriform cortex activity mapped using multisite recording with voltage sensitive dye. Eur J Neurosci. 9:1593-1602.

Luyten L, Casteels C, Vansteenwegen D, van Kuyck K, Koole M, Van Laere K, Nuttin B. 2012. Micro-positron emission tomography imaging of rat brain metabolism during expression of contextual conditioning. J Neurosci. 32:254-263.

Maier E, Lauer S, Brecht M. 2020. Layer 4 organization and respiration locking in the rodent nose somatosensory cortex. J Neurophysiol. 124:822-832.

Maren S. 2001. Neurobiology of Pavlovian fear conditioning. Annu Rev Neurosci. 24:897-931.

Maren S, Aharonov G, Fanselow MS. 1996. Retrograde abolition of conditional fear after excitotoxic lesions in the basolateral amygdala of rats: absence of a temporal gradient. Behav Neurosci. 110:718-726.

Maren S, Holt WG. 2004. Hippocampus and Pavlovian fear conditioning in rats: muscimol infusions into the ventral, but not dorsal, hippocampus impair the acquisition of conditional freezing to an auditory conditional stimulus. Behav Neurosci. 118:97110.

Maren S, Phan KL, Liberzon I. 2013. The contextual brain: implications for fear conditioning, extinction and psychopathology. Nat Rev Neurosci. 14:417-428.

Maviel T, Durkin TP, Menzaghi F, Bontempi B. 2004. Sites of neocortical reorganization critical for remote spatial memory. Science. 305:96-99.

McDonald AJ. 1991. Topographical organization of amygdaloid projections to the caudatoputamen, nucleus accumbens, and related striatal-like areas of the rat brain. Neuroscience. 44:15-33. 
McGeorge AJ, Faull RL. 1989. The organization of the projection from the cerebral cortex to the striatum in the rat. Neuroscience. 29:503-537.

Meissner-Bernard C, Dembitskaya Y, Venance L, Fleischmann A. 2019. Encoding of Odor Fear Memories in the Mouse Olfactory Cortex. Curr Biol. 29:367-380.e4.

Milad MR, Quirk GJ. 2012. Fear extinction as a model for translational neuroscience: ten years of progress. Annu Rev Psychol. 63:129-151.

Mouly A-M, Di Scala G. 2006. Entorhinal cortex stimulation modulates amygdala and piriform cortex responses to olfactory bulb inputs in the rat. Neuroscience. 137:11311141.

Mouly AM, Fort A, Ben-Boutayab N, Gervais R. 2001. Olfactory learning induces differential long-lasting changes in rat central olfactory pathways. Neuroscience. $102: 11-21$.

Mouly AM, Gervais R. 2002. Polysynaptic potentiation at different levels of rat olfactory pathways following learning. Learn Mem. 9:66-75.

Müller G, Pilzecker A. 1900. Experimentelle beiträge zur lehre vom gedächtniss. In Barth JA. editor. Zeitschrift für psychologie. Erg. Bd., I. Leipzig (Germany).

Pape H-C, Pare D. 2010. Plastic synaptic networks of the amygdala for the acquisition, expression, and extinction of conditioned fear. Physiol Rev. 90:419-463.

Paxinos G, Watson C. 2005. The rat brain in stereotaxic coordinates. Sidney (Australia): Elsevier Academic Press.

Phillips RG, LeDoux JE. 1992. Differential contribution of amygdala and hippocampus to cued and contextual fear conditioning. Behav Neurosci. 106:274-285.

Phillips RG, LeDoux JE. 1994. Lesions of the dorsal hippocampal formation interfere with background but not foreground contextual fear conditioning. Learn Mem. 1:34-44. 
Quirk GJ, Armony JL, LeDoux JE. 1997. Fear conditioning enhances different temporal components of tone-evoked spike trains in auditory cortex and lateral amygdala. Neuron. 19:613-624.

Rosenkranz JA, Grace AA. 2002. Dopamine-mediated modulation of odour-evoked amygdala potentials during pavlovian conditioning. Nature. 417:282-287.

Rudy JW. 2009. Context representations, context functions, and the parahippocampalhippocampal system. Learn Mem. 16:573-585.

Sacchetti B, Scelfo B, Tempia F, Strata P. 2004. Long-term synaptic changes induced in the cerebellar cortex by fear conditioning. Neuron. 42:973-982.

Sacco T, Sacchetti B. 2010. Role of secondary sensory cortices in emotional memory storage and retrieval in rats. Science. 329:649-656.

Sevelinges Y, Gervais R, Messaoudi B, Granjon L, Mouly A-M. 2004. Olfactory fear conditioning induces field potential potentiation in rat olfactory cortex and amygdala. Learn Mem. 11:761-769.

Sevelinges Y, Moriceau S, Holman P, Miner C, Muzny K, Gervais R, Mouly A-M, Sullivan RM. 2007. Enduring effects of infant memories: infant odor-shock conditioning attenuates amygdala activity and adult fear conditioning. Biol Psychiatry. 62:10701079.

Sevelinges Y, Sullivan RM, Messaoudi B, Mouly A-M. 2008. Neonatal odor-shock conditioning alters the neural network involved in odor fear learning at adulthood. Learn Mem. 15:649-656.

Sharp FR, Gonzalez MF, Sharp JW, Sagar SM. 1989. c-fos expression and (14C) 2deoxyglucose uptake in the caudal cerebellum of the rat during motor/sensory cortex stimulation. J Comp Neurol. 284:621-636. 
Sierra-Mercado D, Padilla-Coreano N, Quirk GJ. 2011. Dissociable roles of prelimbic and infralimbic cortices, ventral hippocampus, and basolateral amygdala in the expression and extinction of conditioned fear. Neuropsychopharmacology. 36:529538.

Squire LR, Genzel L, Wixted JT, Morris RG. 2015. Memory consolidation. Cold Spring Harb Perspect Biol. 7:a021766.

Staples LG, Hunt GE, Cornish JL, McGregor IS. 2005. Neural activation during cat odor-induced conditioned fear and "trial 2" fear in rats. Neurosci Biobehav Rev. 29:1265-1277.

Sung K-K, Jang D-P, Lee S, Kim M, Lee S-Y, Kim Y-B, Park C-W, Cho Z-H. 2009. Neural responses in rat brain during acute immobilization stress: a [F-18]FDG micro PET imaging study. Neurolmage. 44:1074-1080.

Supple WF, Leaton RN, Fanselow MS. 1987. Effects of cerebellar vermal lesions on species-specific fear responses, neophobia, and taste-aversion learning in rats. Physiol Behav. 39:579-586.

Tang J, Ko S, Ding H-K, Qiu C-S, Calejesan AA, Zhuo M. 2005. Pavlovian fear memory induced by activation in the anterior cingulate cortex. Mol Pain. 1:6.

Tovote P, Esposito MS, Botta P, Chaudun F, Fadok JP, Markovic M, Wolff SBE, Ramakrishnan C, Fenno L, Deisseroth K, Herry C, Arber S, Lüthi A. 2016. Midbrain circuits for defensive behaviour. Nature. 534:206-212.

Uselman TW, Barto DR, Jacobs RE, Bearer EL. 2020. Evolution of brain-wide activity in the awake behaving mouse after acute fear by longitudinal manganese-enhanced MRI. Neurolmage. 222:116975.

Vaaga CE, Brown ST, Raman IM. 2020. Cerebellar modulation of synaptic input to freezing-related neurons in the periaqueductal gray. eLife. 9. 
Vianna DM, Graeff FG, Landeira-Fernandez J, Brandão ML. 2001. Lesion of the ventral periaqueductal gray reduces conditioned fear but does not change freezing induced by stimulation of the dorsal periaqueductal gray. Learn Mem. 8:164-169.

Walker DL, Paschall GY, Davis M. 2005. Glutamate receptor antagonist infusions into the basolateral and medial amygdala reveal differential contributions to olfactory vs. context fear conditioning and expression. Learn Mem. 12:120-129.

Weinberger NM. 2007. Auditory associative memory and representational plasticity in the primary auditory cortex. Hear Res. 229:54-68.

Welker WI. 1964. Analysis of sniffing of the albino rat. Behavior. 22:223-244.

Wendler E, Gaspar JCC, Ferreira TL, Barbiero JK, Andreatini R, Vital MABF, Blaha CD, Winn P, Da Cunha C. 2014. The roles of the nucleus accumbens core, dorsomedial striatum, and dorsolateral striatum in learning: performance and extinction of Pavlovian fear-conditioned responses and instrumental avoidance responses. Neurobiol Learn Mem. 109:27-36.

Wilson DA. 1998a. Habituation of odor responses in the rat anterior piriform cortex. J Neurophysiol. 79:1425-1440.

Wilson DA. 1998b. Synaptic correlates of odor habituation in the rat anterior piriform cortex. J Neurophysiol. 80:998-1001.

Wilson DA, Stevenson RJ. 2003. Olfactory perceptual learning: the critical role of memory in odor discrimination. Neurosci Biobehav Rev. 27:307-328.

Winocur G, Moscovitch M, Bontempi B. 2010. Memory formation and long-term retention in humans and animals: convergence towards a transformation account of hippocampal-neocortical interactions. Neuropsychologia. 48:2339-2356.

Woo C-W, Krishnan A, Wager TD. 2014. Cluster-extent based thresholding in fMRI analyses: pitfalls and recommendations. Neurolmage. 91:412-419. 


\section{Declaration of interest: None}

\section{Data/code availability statement}

The data that support the findings of this study are available from the corresponding author, Philippe Litaudon, upon reasonable request. 
Table 1: Main brain regions showing significant increases in $\left[{ }^{18} \mathrm{~F}\right] \mathrm{FDG}$ uptake between Fear (F1) and Control (C1) conditions for recent memory retention test.

\begin{tabular}{|c|c|c|c|}
\hline $\begin{array}{l}\text { Brain } \\
\text { regions }\end{array}$ & $\begin{array}{l}\text { Structures within brain } \\
\text { regions }\end{array}$ & $\begin{array}{l}\text { Cluster } \\
\text { Number }\end{array}$ & $\begin{array}{l}\text { Fig. } 3 \\
\text { panel }\end{array}$ \\
\hline \multirow{2}{*}{$\begin{array}{l}\text { Primary } \\
\text { olfactory }\end{array}$} & $\mathrm{R}: \mathrm{AON}, \mathrm{aPC}, \mathrm{pPC}, \mathrm{Ent}$ & $3 a, 14,24$ & $a, b, e-g, j, k$ \\
\hline & $L: A O N, a P C, p P C$ & 2,13 & $a, b, d-g$ \\
\hline Frontal & $\mathrm{R}: \mathrm{PL}, \mathrm{Cg}$ & $3 b$ & $a, b$ \\
\hline Cortex & $\mathrm{L}: \mathrm{LO}, \mathrm{Cg}$ & 1,10 & $a, d$ \\
\hline \multirow{2}{*}{ Cortex } & R : S1, S2, Parietal & $7,12,15,17$ & $d, e, f, g$ \\
\hline & $\mathrm{L}: \mathrm{S} 1$ & 5,8 & $c, d$ \\
\hline \multirow{2}{*}{ Striatum } & $\mathrm{R}: \mathrm{CPu}, \mathrm{Acb}$ & 4,16 & $\mathrm{~b}, \mathrm{c}, \mathrm{e}$ \\
\hline & $\mathrm{L}: \mathrm{Acb}, \mathrm{CPu}$ & 6,9 & c-e \\
\hline \multirow{2}{*}{ Thalamus } & $\mathrm{R}:$ dorsal/ventral & 16 & $f, g$ \\
\hline & $\mathrm{L}:$ dorsal & $18 a$ & g \\
\hline \multirow{2}{*}{ Amygdala } & $\mathrm{R}: \mathrm{BLA}$ & 14 & $f$ \\
\hline & L: BLA & 20 & $f, g$ \\
\hline \multirow{2}{*}{$\begin{array}{l}\text { Hippocampal } \\
\text { formation }\end{array}$} & $\mathrm{R}:$ subiculum & 24 & $\bar{j}$ \\
\hline & $\begin{array}{l}\mathrm{L}: \text { dorsal and ventral } \\
\text { hippocampus }\end{array}$ & $18 b, 19,20$ & $g-j$ \\
\hline PAG & L:PAG & 23 & $\mathrm{j}, \mathrm{k}$ \\
\hline \multirow{2}{*}{ Cerebellum } & $\mathrm{R}:$ Crus 2 & 28 & $\mathrm{~m}$ \\
\hline & L: Crus1, Crus2 & $25,26,27$ & $\mathrm{I}, \mathrm{m}$ \\
\hline
\end{tabular}


Notes: R: right hemisphere. L: left hemisphere. Cluster number corresponds to clusters defined in supplementary Table 1 and to numbers indicated on figure 3 panels. Abbreviations: AON (anterior olfactory nucleus), aPC (anterior piriform cortex), pPC (posterior piriform cortex), Ent (entorhinal cortex), PL (prelimbic cortex), Cg (cingulate cortex), LO: lateral orbital cortex, S1 (primary somatosensory cortex), S2 (secondary somatosensory cortex), $\mathrm{CPu}$ (caudate putamen), Acb (accumbens nucleus), BLA (basolateral amygdaloid complex), PAG (periaqueductal gray). 
Table 2: Brain regions showing significant increases in [ $\left.{ }^{18} \mathrm{~F}\right] \mathrm{FDG}$ uptake between Fear and Control conditions for remote memory retention test.

\begin{tabular}{|c|c|c|c|c|c|c|c|}
\hline \multirow{2}{*}{$\begin{array}{l}\text { Cluster } \\
\mathrm{Nb}\end{array}$} & \multirow{2}{*}{$\begin{array}{l}\text { Regions within } \\
\text { the cluster }\end{array}$} & \multirow{2}{*}{$\begin{array}{l}\text { Cluster } \\
\text { size } \\
\left(\mathrm{mm}^{3}\right)\end{array}$} & \multicolumn{2}{|c|}{ Cluster Peak } & \multicolumn{3}{|c|}{ Coordinates (mm) } \\
\hline & & & T-value & $p$-value & $\mathbf{x}$ & $\mathbf{y}$ & $\mathbf{z}$ \\
\hline 1 & Right $\mathrm{pPC}$ & 0.27 & 5.18 & $<10^{-3}$ & 5.0 & -10.1 & -0.9 \\
\hline
\end{tabular}

Notes: Values $x, y, z$ are the coordinates of the peak activation centers in the Paxinos and Watson stereotaxic space (Paxinos and Watson 2005). The x-coordinate corresponds to the distance lateral from the midline between the hemispheres (positive values for spots located on the right side) (L, Left; $R$, Right); the $y$-coordinate denotes the dorsoventral position; the z-coordinate indicates the position relative to Bregma (positive values for sections anterior to Bregma). Abbreviations: pPC (posterior piriform cortex). 


\section{Figure captions}

\section{Figure 1: Training and imaging protocol.}

During the conditioning session, the animals in the Fear group $(F)$ were trained with 10 odor-shock pairings, while the animals in the Control group (C) received 10 odor presentations but no shock. For both groups, a retention test was conducted $24 \mathrm{~h}$ (recent memory, F1 \& C1) and 30 days (remote memory, F2 \& C2) later using ten odor presentations during which the animal's freezing response was assessed. Five minutes before each retention test, the animals received a $\left[{ }^{18} \mathrm{~F}\right] \mathrm{FDG}$ intravenous injection. At the end of each retention test, the animals were anesthetized for the PET imaging session.

\section{Figure 2: Freezing response}

Percentage of freezing (mean + SEM) in response to odor presentation in Control group $(C)$ and Fear group $(F)$ during recent $(C 1, F 1)$ and remote $(C 2, F 2)$ memory retention tests. Open circles show single data points. *: significant difference with the control group, $\mathrm{p}<0.001$.

Figure 3: Voxel-based SPM results for the T-contrast Fear versus Control for recent memory retention test.

From a to m: Coronal slices through T-maps showing clusters of significant increases in $\left[{ }^{18} \mathrm{~F}\right] \mathrm{FDG}$ uptake overlaid on an MRI template. The images follow neurological convention, with the left side corresponding to the left hemisphere. Red and white numbers on panels correspond to cluster numbers in table 1 and supplementary table 1. 
Figure 4: Voxel-based SPM results for the T-contrast Fear versus Control for remote memory retention test.

Coronal slice through T-maps showing cluster of significant increases in $\left[{ }^{18} \mathrm{~F}\right] \mathrm{FDG}$ uptake overlaid on an MRI template. The image follows neurological convention. White number on panel corresponds to cluster number in table 2 


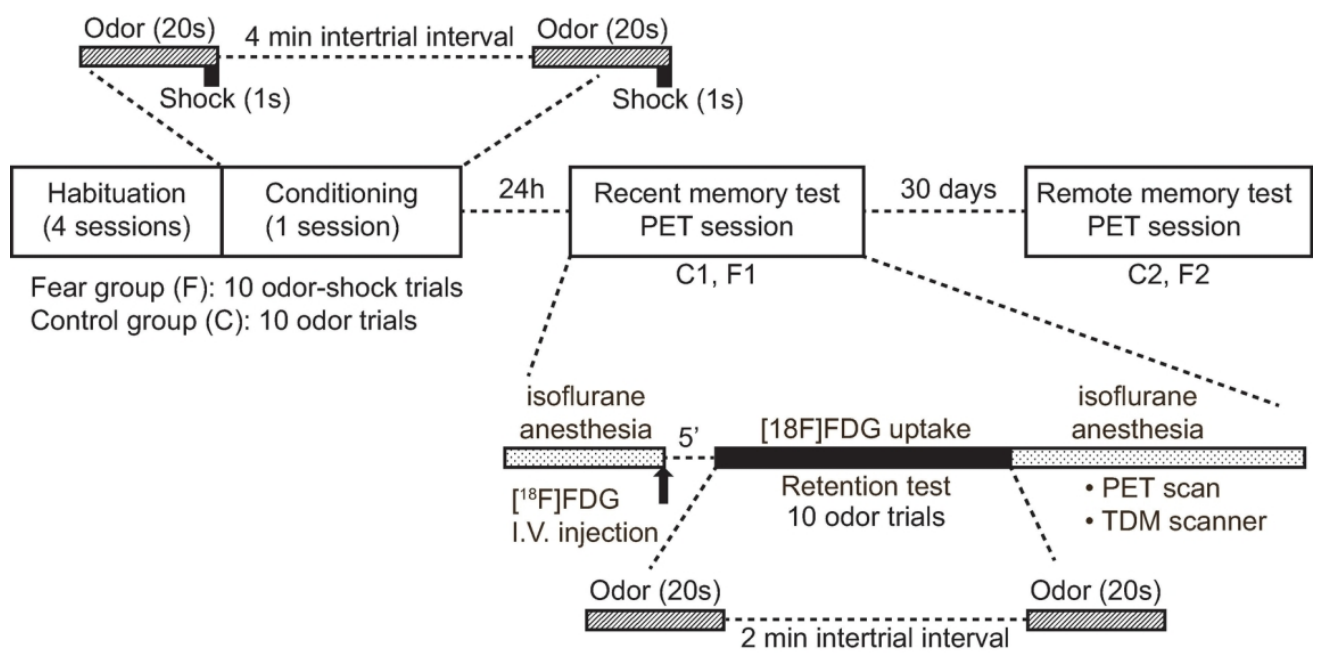

Figure 1: Training and imaging protocol.

During the conditioning session, the animals in the Fear group $(F)$ were trained with 10 odor-shock pairings, while the animals in the Control group (C) received 10 odor presentations but no shock. For both groups, a retention test was conducted $24 \mathrm{~h}$ (recent memory, F1 \& C1) and 30 days (remote memory, F2 \& C2) later using ten odor presentations during which the animal's freezing response was assessed. Five minutes before each retention test, the animals received a [18F]FDG intravenous injection. At the end of each retention test, the animals were anesthetized for the PET imaging session. 


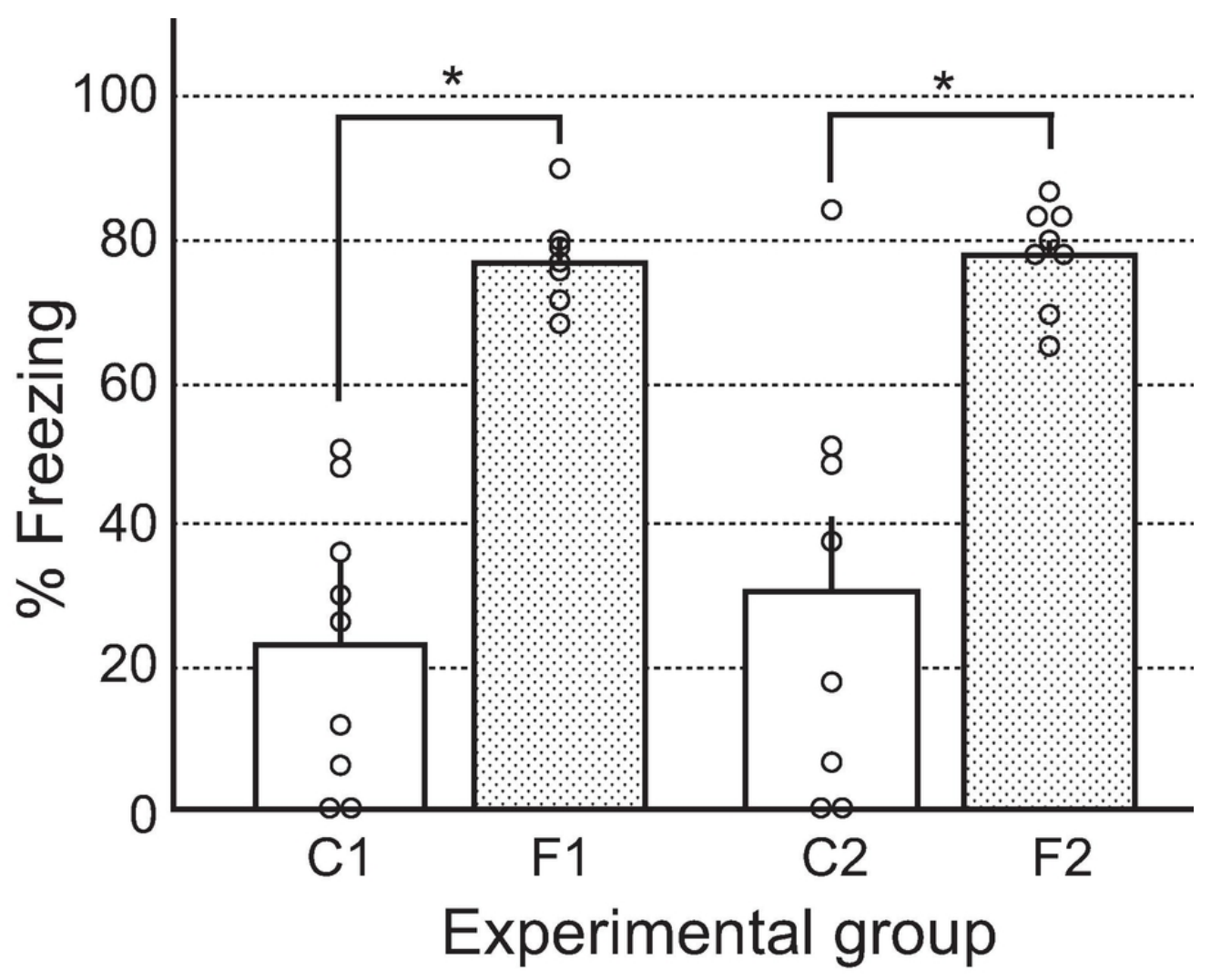

Figure 2: Freezing response

Percentage of freezing (mean + SEM) in response to odor presentation in Control group (C) and Fear group $(F)$ during recent $(C 1, F 1)$ and remote $(C 2, F 2)$ memory retention tests. Open circles show single data points. *: significant difference with the control group, $\mathrm{p}<0.001$.

$78 \times 63 \mathrm{~mm}(300 \times 300 \mathrm{DPI})$ 

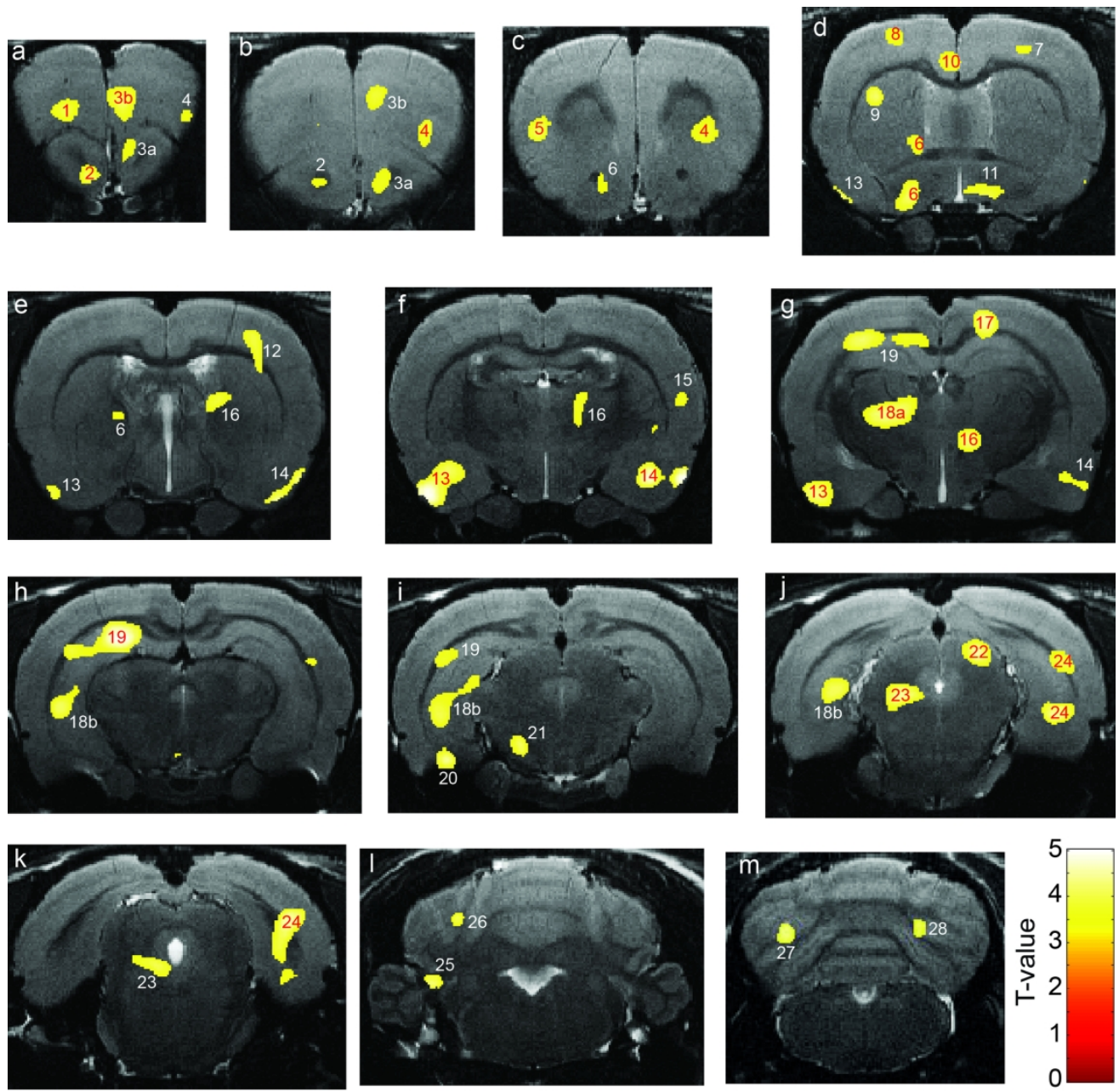

Figure 3: Voxel-based SPM results for the T-contrast Fear versus Control for recent memory retention test. From a to $\mathrm{m}$ : Coronal slices through T-maps showing clusters of significant increases in [18F]FDG uptake overlaid on an MRI template. The images follow neurological convention, with the left side corresponding to the left hemisphere. Red and white numbers on panels correspond to cluster numbers in table 1 and supplementary table 1 

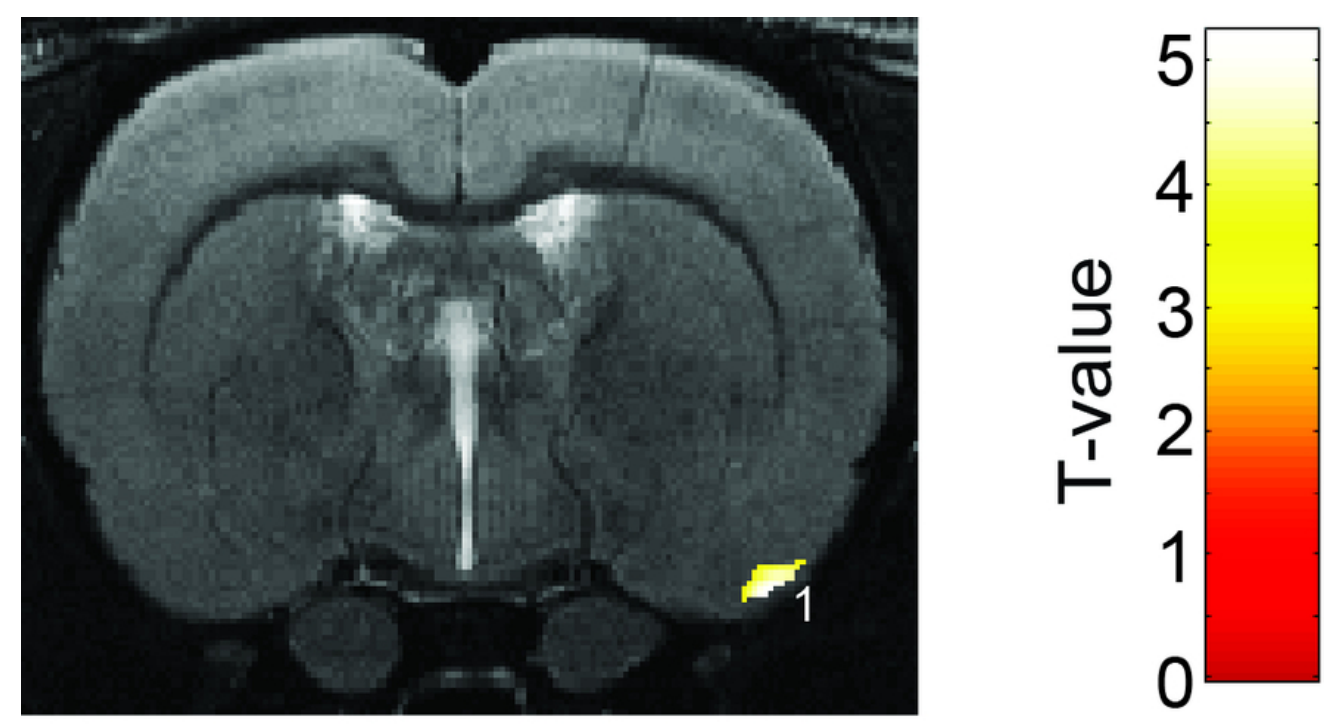

Figure 4: Voxel-based SPM results for the T-contrast Fear versus Control for remote memory retention test. Coronal slice through T-maps showing cluster of significant increases in [18F]FDG uptake overlaid on an MRI template. The image follows neurological convention. White number on panel corresponds to cluster number in table 2.

$74 \times 41 \mathrm{~mm}(300 \times 300$ DPI $)$ 


\begin{tabular}{|c|c|c|c|c|c|c|c|}
\hline \multirow{2}{*}{$\begin{array}{c}\text { Cluster } \\
\text { Nb }\end{array}$} & \multirow{2}{*}{$\begin{array}{l}\text { Fig. } 3 \\
\text { Panel }\end{array}$} & \multirow{2}{*}{$\begin{array}{c}\text { Cluster } \\
\text { size } \\
\left(\mathrm{mm}^{3}\right)\end{array}$} & \multicolumn{2}{|c|}{ Cluster Peak } & \multicolumn{3}{|c|}{$\begin{array}{c}\text { Coordinates } \\
(\mathrm{mm})\end{array}$} \\
\hline & & & T-value & p-value & $\mathbf{x}$ & $y$ & $\mathbf{z}$ \\
\hline 1 & $a$ & 4.20 & 4.23 & $<10^{-3}$ & -0.6 & -5.9 & 6.1 \\
\hline 2 & $a, b$ & 0.90 & 4.22 & $<10^{-3}$ & -0.8 & -7.5 & 3.9 \\
\hline 3 & $a, b$ & 5.54 & 4.47 & $<10^{-3}$ & 0.9 & -3.8 & 3.6 \\
\hline 4 & $b, c$ & 1,78 & 4.47 & $<10^{-3}$ & 3.3 & -5.6 & 2.4 \\
\hline 5 & $\mathrm{C}$ & 1.05 & 4.15 & $<10^{-3}$ & -4.5 & -5.6 & 2.0 \\
\hline 6 & c-e & 5.22 & 4.49 & $<10^{-3}$ & -2.1 & -8.7 & 0.6 \\
\hline 7 & $d$ & 0.38 & 3.67 & 0.001 & 3.2 & -2.5 & 0.4 \\
\hline 8 & $d$ & 0.50 & 3.74 & $<10^{-3}$ & -2.8 & -2.1 & 0.2 \\
\hline 9 & $d$ & 0.46 & 4.01 & $<10^{-3}$ & -3.9 & -4.7 & -0.0 \\
\hline 10 & $d$ & 0.64 & 3.94 & $<10^{-3}$ & -0.4 & -3.2 & -0.2 \\
\hline 11 & $d$ & 1.84 & 4.36 & $<10^{-3}$ & 0.4 & -8.9 & -0.5 \\
\hline 12 & $\mathrm{e}$ & 1.38 & 4.22 & $<10^{-3}$ & 4.1 & -3.3 & -1.5 \\
\hline 13 & $d-g$ & 4.15 & 4.99 & $<10^{-3}$ & -5.4 & -9.9 & -1.7 \\
\hline 14 & $e-g$ & 3.53 & 4.68 & $<10^{-3}$ & 6.2 & -9.2 & -1.9 \\
\hline 15 & $f$ & 0.55 & 3.90 & $<10^{-3}$ & 6.3 & -5.5 & -2.5 \\
\hline 16 & $f, g$ & 3.04 & 4.04 & $<10^{-3}$ & 1.2 & -7.3 & -3.5 \\
\hline 17 & $g$ & 1.84 & 4.34 & $<10^{-3}$ & 1.9 & -1.8 & -3.7 \\
\hline 18 & $g-j$ & 9.77 & 4.23 & $<10^{-3}$ & -4.3 & -5.2 & -6.4 \\
\hline 19 & $g-i$ & 7.28 & 4.71 & $<10^{-3}$ & -3.1 & -3.1 & -5.2 \\
\hline 20 & $\mathrm{i}$ & 0.48 & 4.10 & $<10^{-3}$ & -5.4 & -8.6 & -6.0 \\
\hline 21 & $\bar{i}$ & 0.37 & 3.90 & $<10^{-3}$ & -2.1 & -7.9 & -6.0 \\
\hline 22 & $\mathrm{j}$ & 1.36 & 4.13 & $<10^{-3}$ & 1.7 & -3.7 & -7.0 \\
\hline 23 & $\mathrm{j}, \mathrm{k}$ & 3.65 & 4.34 & $<10^{-3}$ & -1.9 & -5.7 & -7.2 \\
\hline 24 & $\mathrm{j}, \mathrm{k}$ & 5.46 & 4.55 & $<10^{-3}$ & 5.2 & -6.5 & -7.4 \\
\hline 25 & 1 & 1.04 & 4.03 & $<10^{-3}$ & -4.7 & -7.4 & -10.5 \\
\hline 26 & 1 & 0.96 & 3.96 & $<10^{-3}$ & -3.4 & -4.6 & -10.7 \\
\hline 27 & $\mathrm{~m}$ & 0.56 & 4.06 & $<10^{-3}$ & -3.8 & -5.1 & -12.8 \\
\hline 28 & $\mathrm{~m}$ & 0.37 & 4.04 & $<10^{-3}$ & 2.3 & -4.9 & -13.2 \\
\hline
\end{tabular}

Supplementary Table 1: Clusters showing significant increases in $\left[{ }^{18} \mathrm{~F}\right] \mathrm{FDG}$ uptake between Fear (F1) and Control (C1) conditions for recent memory retention test.

Values $x, y, z$ are the coordinates of the peak activation centers in the Paxinos and Watson stereotaxic space (Paxinos and Watson, 2005). The $x$-coordinate corresponds to the distance lateral from the midline between the hemispheres (positive values for spots located on the right side) (L, Left; R, Right); the $y$-coordinate denotes the dorsoventral position; the $z$-coordinate indicates the position relative to Bregma (positive values for sections anterior to Bregma). Cluster numbers corresponds to red and white numbers on figure 3 panels. 